\title{
Effect of Carrier Materials in Inverse Anaerobic Fluidized Bed Reactor for Treating High Strength Organic Waste Water
}

D Thaiyalnayaki and R Sowmeyan*

Periyar Maniammai University, Vallam Thanjavur, Tamilnadu, India

\begin{abstract}
This article explains that thermo cool, plastic beads, cork, teak wood and perlite were tried as carrier materials in the lab-scale reactor towards treating high strength organic wastewater by using inverse anaerobic fluidized bed reactor (IAFBR). Organic wastewater of great strength (molasses) is pronounced for its high chemical oxygen demand (COD) of 45,000 to $75,000 \mathrm{mg} / \mathrm{l}$ and low $\mathrm{pH}$ values of 4.3 to 5.3 . The results of this study highlighted the selection, physical properties and performance of carrier materials on biomass retention. This study has also clearly indicated that perlite proves to be a suitable carrier material for high biomass retention and improvement of the reactor performances in a short time of operation.
\end{abstract}

Keywords: High strength organic wastewater; Types of carrier material; Properties of carrier material; Biomass retention; Anaerobic digestion

\section{Introduction}

Inverse fluidized bed reactor method was suggested for anaerobic treatment of wastewater [1]. Particles with a specific gravity less than the liquid were fluidized downward by a concurrent flow of liquid. Inverse fluidization technology has been adopted for the anaerobic digestion of red wine distillery wastewater. It has shown better results compared to other biological reactors $[1,2]$ employed ground perlite obtained from an expanded volcanic rock and used as carrier material which had significant effect on formation of biofilm over carrier material and improved the reactor performances. Perlite was found to be effective when compared to other carrier materials like cork, polyethylene or polypropylene, teak, plastic beads, and thermo cool.

Karamanev and Nikolov [3] have described the application of inverse fluidization in wastewater treatment from laboratory to fullscale bioreactors. The biofilm, growing on the surface of support particles, increased the overall bioparticle (support particle plus biofilm) diameter. Under the fluidized condition, each media provided a large surface area for biomass growth and attachment. It enabled the attainment of high reactor biomass hold-up and promoted the system efficiency and stability. Thus higher organic loading rates and greater resistance to inhibitors are increased. But there is a lack of information concerning biomass growth on carrier material, inhibition on biomass growth and washout of biomass from carrier materials.

Hence this work summarizes physical properties of various carrier materials, their selection criteria and their performance of the carrier material on biomass retention in an inverse anaerobic fluidized bed reactor for treating high strength organic wastewater.

\section{Materials and Methods}

\section{Carrier materials and their selection}

The selection of material for a fluidized bed reactor should have many aspects including the sizing of equipment for the biological process and the operation of the system [4]. The carrier material properties are highly influenced by the reactor hydraulics and biofilm thickness [5]. Prior to the selection of carrier materials, both physical and chemical characteristics of the media should be considered. The physical characteristics included size, shape, particle density, hardness and surface area [6].

In IAFBRs the biofilm formation is strongly influenced by the surface properties of the support media. Thus, porosity and roughness of the support surface play a major role during the initial start-up period. Support of the porous or rough surface are very much essential and hence recommended [5] for quick start up. One of the most advantages of fluidized bed reactors is the large surface area available for biofilm formation and attachment, which allows higher concentration of biomass. Porous materials such as GAC (granular activated carbon), sepiolite, pumice and kaolinite offer internal pores. Surface area is increased because of its size and color. This increment could be of two or three orders of magnitude [4]. The size of the particle influences the available surface for attachment as well as many characteristics of fluidization and consequent mass transfer [4]. To reduce the diameter over the specific area and the operating costs the superficial fluidization characteristics velocity should be kept at low values, forcing the use of small size particles, which also provide greater surface area available for colonization and recommended sizes ranging between $0.1 \mathrm{~mm}$ and $0.7 \mathrm{~mm}$ [4]. Support media for IAFBR should have a uniform size and shape, in order to achieve a uniform particle fluidization throughout the reactor height without diffusion limitations and channeling effect [5]. One of the assumptions made when developing models is that the biofilm is uniformly distributed along the carrier, forming a layer of equal thickness. Visual evaluation shows biofilm accumulation that fills the crevices and voids where shear forces are smaller and bald areas where exposure is higher [4].

The density of the material is another important variable for selecting a medium. This factor affects the hydrodynamics of the fluidized bed

*Corresponding author: R Sowmeyan, Periyar Maniammai University, Vallam Thanjavur, Tamilnadu, India Tel: 91-4362-264600; Fax: 91-4362-264660; E-mail: sowmeyanr@yahoo.co.uk

Received November 21, 2011; Accepted March 20, 2012; Published March 23 2012

Citation: Thaiyalnayaki D, Sowmeyan R (2012) Effect of Carrier Materials in Inverse Anaerobic Fluidized Bed Reactor for Treating High Strength Organic Waste Water. J Environment Analytic Toxicol 2:134. doi:10.4172/2161-0525.1000134

Copyright: (C) 2012 Thaiyalnayaki D, et al. This is an open-access article distributed under the terms of the Creative Commons Attribution License, which permits unrestricted use, distribution, and reproduction in any medium, provided the original author and source are credited. 
Citation: Thaiyalnayaki D, Sowmeyan R (2012) Effect of Carrier Materials in Inverse Anaerobic Fluidized Bed Reactor for Treating High Strength Organic Waste Water. J Environment Analytic Toxicol 2:134. doi:10.4172/2161-0525.1000134

Page 2 of 5

and has a direct relationship with power consumption process changes and economy. The particle density closer to the density of the fluidizing liquid, the superficial velocity for minimum fluidization and $20 \%$ bed expansion becomes close [4]. The hydrodynamic control of the bed is difficult. The cost of the material is obviously another aspect to consider because it influences process efficiency and economy of the system [4].

The artificial supports, like open pores entered glass, ceramics or plastics beads show excellent immobilization properties, but are highly expensive. The benefits of such media are controversial, because the economic advantages due to the size reduction of the reactor are often overweighed by the high support costs [5]. Among the chemical properties the most important are chemical compatibility and adsorption [4].

\section{Experimental set-up}

The reactor set up used in the experimental studies is shown in figure 1 . This was used throughout the course of this study. The tank is made of medium density perfex sheet. It has a nominal capacity of 5.03 lits, a diameter of $0.08 \mathrm{~m}$ and a height of $1 \mathrm{~m}$. The reactor was filled with the solid carrier material with $55 \%$ of its active volume.

Influent from feed tank is pumped into the reactor with constant loading rate of $6.11 \mathrm{~kg} / \mathrm{m}^{3}$.d during startup period and gradually increased up to $34 \mathrm{~kg} / \mathrm{m}^{3}$.d using down flow valve. The HTR was decreased from $2 \mathrm{~d}$ to $0.16 \mathrm{~d}$ during operation time. From top of the reactor, the influent gets sprayed in down flow mode. This prevented the channeling effect and provided the expansion of bed with low energy requirements. Flow in the reactor was regulated by rotometer, which was placed near the pump. The $\mathrm{pH}$ in the reactor was adjusted to 7 with $\mathrm{NaOH}$ during the start up period, and then it was naturally maintained between 7 and 7.5 without any addition of $\mathrm{NaOH}$.

Anaerobic conditions were maintained by spraying nitrogen gas into the reactor. The lower part of the reactor was connected to the input pipe where the recycle and the nutrient feeding flow together. The flow distributor and the gas outlet were placed at the removable cap covering the top section. The gas outlet was connected to gas meter. The gas produced in the reactor was collected and stored in a collection measurement tank. A water column was used to measure the biogas production.

\section{Reactor inoculations and start-up}

The reactor was filled with the solid carrier materials up to 55\% of its active volume. The reactor was fed with a synthetic wastewater containing glucose as a carbon substrate with rumen as inoculum in a ratio of 2:1. Rumen is one of the by products obtained from slaughterhouses of cattle, sheep and goat. The most abundant rumen bacterial species are the generalists or non-specific such as Prevotella ruminicola and Butyrivit fibrosolvens, which degraded into a wide range of polymers, Selenomonas ruminantium that utilized a variety of end-products [7]. After sampling, the rumen contents were strained through four layers of $1 \mathrm{~mm}$ nylon mesh. The filter strain was allowed to ferment for two days in an airtight container. The fermented solution was used as inoculum in this study. The composition of synthetic wastewater for the test is as follows (per liter): $12.5 \mathrm{~g}$ glucose, $7.12 \mathrm{~g}$ $\mathrm{K}_{2} \mathrm{HPO}_{4}, 1.36 \mathrm{~g} \mathrm{KH}_{2} \mathrm{PO}_{4}, 1.227 \mathrm{~g}$ urea, $0.06 \mathrm{~g} \mathrm{CaCl}_{2}$ and $0.008 \mathrm{~g} \mathrm{FeCl}_{3}$ The reactor was monitored for temperature, flow rate and $\mathrm{pH}$ and TSS and VFA have been routinely analyzed. The influent OLR was held initially at $6.11 \mathrm{~kg}$ of $\mathrm{COD} / \mathrm{m}^{3} . \mathrm{d}$ with a constant HRT of 2.0 days. The OLR was then increased by additional input flow rate. There is no need for sludge recycling in this reactor.

\section{Physical properties of carrier materials}

Carrier materials such as thermo cool, plastic beads, cork, teak wood and perlite were tried in the lab-scale reactor. The physical properties of the different carrier materials are furnished in the table 1.

\section{Biomass growth and carrier colonization}

The average biofilm size on particles was estimated from diameter measurements using an optical microscope. The diameter was determined approximately for 50 particles for each sample. Over the first 9 days, very few changes occurred in the reactor on the aspect of the carrier particles. The adjunction of trace elements and nitrogen source in the influent mixture quickly modified the aspect of the reactor. Firstly, the color of the particles obviously turned from white to intense grey. Microscopic observations confirmed the presence of biomass on the carrier, either as local outgrowth colonies, or as uniform covering of the particles. The biomass coverage on the particle was uniform. A large number of particles were covered by a thin biofilm of constant thickness.

The amount of VAS per gram of carrier was measured once a reasonable amount was established on the particles. The amount of attached biomass on sampled bioparticles from the IAFBR was determined by the following modified procedures [8]. Firstly, $15 \mathrm{~mL}$ of bioparticles were placed in a $50 \mathrm{~mL}$ glass flask to dry and be weighed at $110^{\circ} \mathrm{C}$ during $24 \mathrm{~h}$. Afterwards, bioparticles were dissolved with $4 \mathrm{~N}$ $\mathrm{NaOH}$ solution, at $110^{\circ} \mathrm{C}$ for $2 \mathrm{~h}$, and then they were agitated for 20 min with approximately $5 \mathrm{~g}$ of glass beads. Finally, they were rinsed with hot deionised water and then dried and weighed at $110^{\circ} \mathrm{C}$ for $24 \mathrm{~h}$.

\section{Results and Discussion}

\section{Performance of the carrier material on biomass retention}

Different carrier materials were used and their performances were evaluated. The diameter, moisture content, specific wet density, specific dry density and specific surface area of the carrier materials were determined. The performance of various carrier materials used in the study such as teak wood, thermocool, plastic beads, cork and perlite were studied on the basis of biomass retention. Biomass development and attachment were considered to be the vital factors in determining the performance efficiency of an inverse anaerobic fluidized bed reactor [9]. The amount of biomass retained among the carriers was determined by measuring the attached volatile solids of sludge in the

\begin{tabular}{|c|c|c|c|c|c|c|}
\hline S. No & Description & Thermo Cool & Plastic Beads & Cork & Teak wood & Perlite \\
\hline 1 & Mean diameter $(\varphi)$ in $\mathrm{mm}$ & 5 & 2 & 1 & 2 & 1 \\
\hline 2 & Moisture content $(m)$ in $\%$ & 32 & 6 & 45 & 47 & 43 \\
\hline 3 & Specific gravity $(\mathrm{G})$ & 1 & 1.2 & 0.90 & 3.1 & 1.8 \\
\hline 4 & Specific dry density $(\mathrm{pd})$ in $\mathrm{Kg} / \mathrm{m}^{3}$ & 90 & 180 & 155 & 200 & 205 \\
\hline 5 & Specific wet density $(\mathrm{pd})$ in $\mathrm{Kg} / \mathrm{m}^{3}$ & 160 & 200 & 210 & 255 & 295 \\
\hline 6 & Specific surface area (Sa) in $\mathrm{m}^{2} / \mathrm{m}^{3}$ & 7010 & 6090 & 5010 & 6085 & 7030 \\
\hline
\end{tabular}

Table 1: Physical properties of different carrier materials. 
Citation: Thaiyalnayaki D, Sowmeyan R (2012) Effect of Carrier Materials in Inverse Anaerobic Fluidized Bed Reactor for Treating High Strength Organic Waste Water. J Environment Analytic Toxicol 2:134. doi:10.4172/2161-0525.1000134

individual carrier material. Attached biomass is expressed as $\mathrm{g}_{\mathrm{AvS}} / \mathrm{g}_{\text {solid. }}$ The variation of biomass concentration in different carrier materials is represented in figure 2-6 during the start-up phase.

The start-up operation was conducted over period of 65 days. During this period, the HRT was decreased stepwise from 5 to 3 days by increasing the OLR from 2.65 to $6.11 \mathrm{~kg}$ of $\mathrm{COD} / \mathrm{m}^{3} . \mathrm{d}$. During the reactor start-up of the total gas production, COD removal efficiencies and $\mathrm{pH}$ were used as performance indication parameters. The biomass concentration was measured by stripping off the solids and its volatile solids contents.

Variation of biomass concentration on teak: Figure 2 shows the variation of biomass concentration on teak with operation time. In the first 5 days the biomass development over the carrier material was much below the concentration of $0.0017 \mathrm{~g}_{\mathrm{AVS}} / \mathrm{g}_{\text {solid. }}$ After the 7 th day onwards, the biomass growth on carriers was absent. This might be due to physical and other characteristics of this carrier material which inhibit the microbial attachment with carriers.

Variation of biomass concentration on thermocool: The development of biomass on thermocool with operation time is given in the figure 3. Biofilm formation over this carrier was comparatively good with that of the teak the during first 15 days with varying concentration. The retention of biomass by this carrier was not highly satisfactory over the operation time. After the 15th day, the biofilm got itself washed out from the carrier. The failure of this carrier material supporting the microorganisms might be due to the same reason by which teak failed.

Variation of biomass concentration on plastic beads: The results shown by the plastic beads were excellent over a period of 15 days with retention of $0.02 \mathrm{~g}_{\mathrm{AVS}} / \mathrm{g}_{\text {solid. }}$ However, it could not sustain over the operation time. The variation of biomass growth over plastic beads is given in figure 4 . On the 16th day, the growth of microorganisms sharply decreased to zero.

Variation of biomass concentration on cork: The biofilm formation over cork showed very poor performance compared with



Figure 1: Inverse Anaerobic Fluidized bed Reactor (IAFBR).

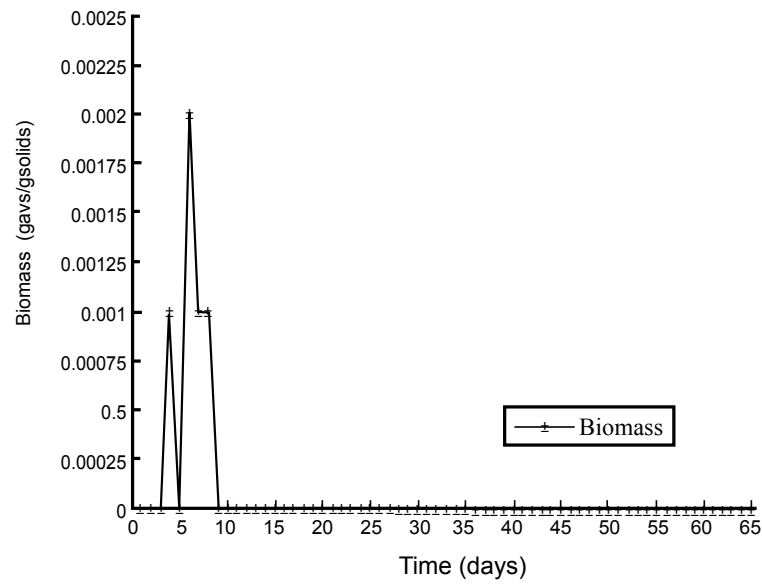

Figure 2: Variation of biomass concentration on teak.

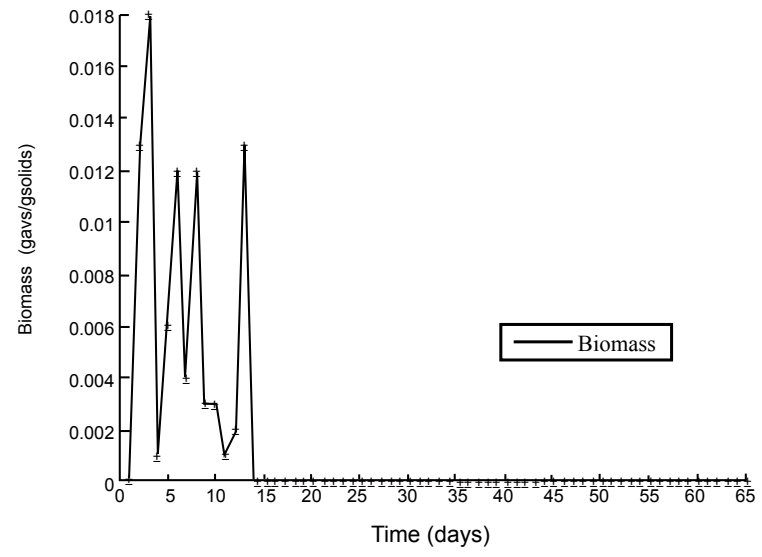

Figure 3: Variation of biomass concentration on thermocool

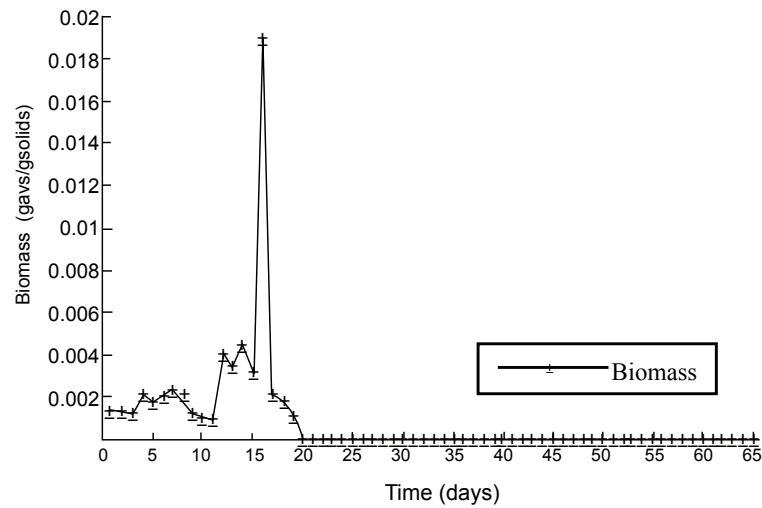

Figure 4: Variation of biomass concentration on plastic beads.

any other carrier used in this study. The growth pattern of the biomass curve of cork is depicted in figure 5 . The concentration and retention of biomass over this carrier was much lower compared to that of any other carrier. The washout of biomass from this carrier took place in less than eight days.

Variation of biomass concentration on perlite: The performance 
Citation: Thaiyalnayaki D, Sowmeyan R (2012) Effect of Carrier Materials in Inverse Anaerobic Fluidized Bed Reactor for Treating High Strength Organic Waste Water. J Environment Analytic Toxicol 2:134. doi:10.4172/2161-0525.1000134

Page 4 of 5

of the carrier materials was evaluated based on solids retention. In less than 15 days, except for perlite, all other carriers showed poor biomass growth and during the end of the operation the biomass growth was found to be nil. Biofilm development and biofilm formation on these carrier materials depend on specific surface area, total pore volume, mean diameter and chemical composition $[10,11]$. These characteristics might be lacking and inadequate in all carriers other than perlite. It was evident from this study that microbial attachment and biofilm formation was accelerated by the large surface, low wet density and porous micro carriers [12]. During the reactor start-up and reactor progress biomass coverage on perlite was found to be uniform; a large number of particles were covered regularly by a thin biofilm of constant thickness. This means that the reactor possess a high biomass retention capacity, and thus have higher performance indices. The capability of perlite for biomass retention with operation time is shown in figure 6.

\section{Discussion}

The biomass activity in the reactor was considered a dynamic system involving equilibrium between growth and biofilm shearing. The experimental study [13] also revealed biofilm development and biomass formation by methanogens surviving under specific

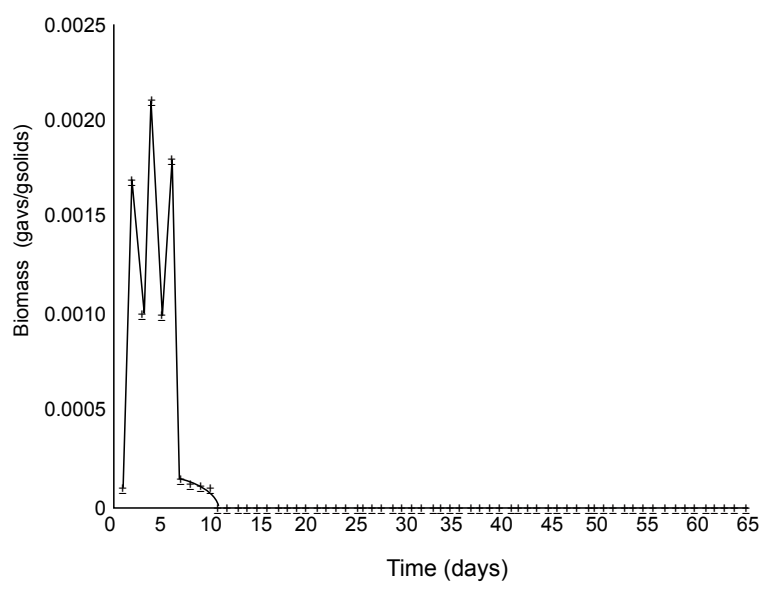

Figure 5: Variation of biomass concentration on cork.

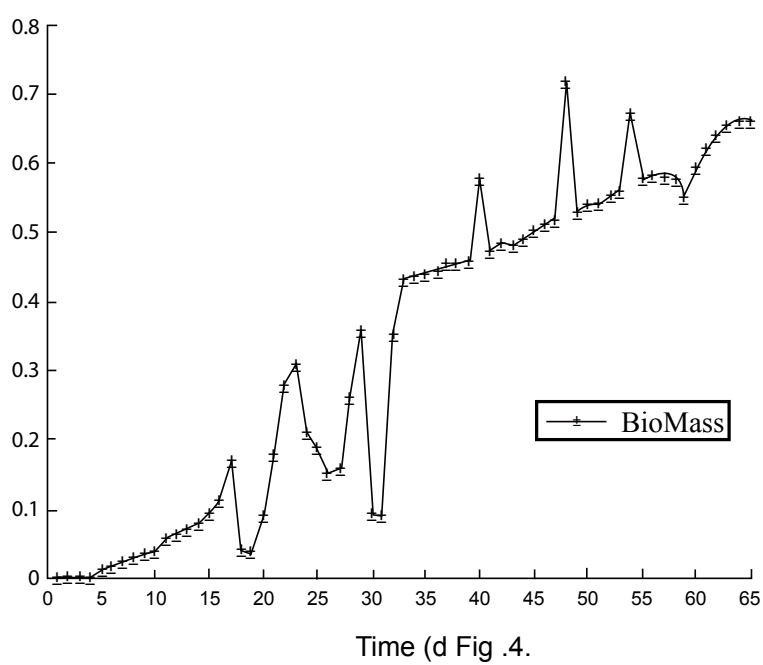

Figure 6: Variation of biomass concentration on perlite. experimental conditions such as $\mathrm{pH}$, temperature, turbulence and wastewater composition. In the earlier stages of operation, very few changes occurred in the reactor concerning the aspect of the carrier particle. The addition of trace elements and nitrogen source in the influent mixture quickly modified the aspect of the reactor. In the inverse fluidized bed with a down flow liquid fluidization using perlite as biomass carrier, the OLR was increased from 3 to $15 \mathrm{~kg}$ of COD/ $\mathrm{m}^{3}$.d in 60 days of operation, but the reactor became destabilized and the carbon removal in terms of COD was only $55 \%$ at the end of the experiment and input was compulsorily decreased [1]. The carrier material was found to be a very important factor, because biomass accumulation brings about changes in particle volume and density, affecting the whole system.

Perlite was found to be a good carrier in the anaerobic digestion of high strength organic wastewater [13]. It allowed a high biomass hold-up, with minimum particle wash out, because of its density. It was inferred that the biomass was $0.66 \mathrm{~g}_{\mathrm{AVS}} / \mathrm{g}_{\text {solids }}$ on day 65 . A comparison with earlier study reactors treating the same kind of effluents was made [14]. In inverse fluidized bed [15] the quantum of biomass was close to $0.2 \mathrm{~g} / \mathrm{g}$ of solid at the end of 90 days. It was found that perlite was mainly responsible for high biomass retention and improvement of the reactor performances in short operation time.

\section{Conclusion}

A new kind of anaerobic reactor with attached biomass, inverse anaerobic fluidized bed reactor is tested. It was found that the carrier material played an important role, by bringing changes in particle volume and density, affecting the whole system. Perlite is identified to be a good carrier for anaerobic digestion of high strength organic wastewater over other carrier materials were used in this study. This is because of its density and high biomass hold-up, with minimum particle washout. In this reactor, microbial adhesion, and a fluidization wastewater is greatly influenced by floating solid carrier. In over all analysis of various carrier materials, perlite is proved to be effective in an inverse anaerobic fluidized bed reactor in the treatment of high strength organic effluent.

\section{References}

1. García-Calderón D, Buffière $P$, Moletta R, Elmaleh S (1998) Influence of biomass accumulation on bed expansion characteristics of a down-flow anaerobic fluidized bed reactor. Biotechnol Bioeng 57: 136-144.

2. Gangagni Rao A, Venkata Naidu G, Krishna Prasad K, Chandrasekhar Rao N Venkata Mohan S, et al. (2005) Anaerobic treatment of wastewater with high suspended solids from a bulk drug industry using fixed film reactor (AFFR). Bioresour Technol 96: 87-93

3. Karamanev D, Nikolov G (1996) Inverse fluidization in wastewater treatment Environ Prog 15: 194-196.

4. Iza J, Palencia JI, Fdz-Polanco F (1990) Wastewater management in a suga beet factory. A case study of comparison between anaerobic Technologies. Water Sci Technol 22: 123- 130.

5. Hickey RF, Wu WM, Veiga MC, Jones R (1991) Start-Up, Operation, Monitoring and Control of High-Rate Anaerobic Treatment Systems. Water Sci Techno 24: $207-255$

6. Marin P, Alkalay D, Guerrero L, Chamy R, Schiappacasse MC (1999) Design and 326 start-up of an anaerobic fluidized bed reactor. Water Sci Technol 40 32763-32770.

7. Stewart CS, Fllint HJ, Bryant MP (1988) The Rumen Bacteria. The Rumen Microbial Ecosystem 2:10-72.

8. Chen CY, Chen SD (2000) Biofilm characteristics in biological denitrification biofilm reactors. Water Sci Technol 4: 147-154. 
Citation: Thaiyalnayaki D, Sowmeyan R (2012) Effect of Carrier Materials in Inverse Anaerobic Fluidized Bed Reactor for Treating High Strength Organic Waste Water. J Environment Analytic Toxicol 2:134. doi:10.4172/2161-0525.1000134

Page 5 of 5

9. Michaud S, Bernet N, Buffiere P, Roustan M, Moletta R (2002) Methane yield as a monitoring parameter for the start-up of anaerobic fixed film reactors. Water Res 36: 1385-1391.

10. Heijnen JJ, Mulder A, Enger W, Hocks F (1989) Review on the application of anaerobic fluidized bed reactors in wastewater treatment. Chem Eng J 41 : B37- B50.

11. Breitenbücher K, Siegl M, Knupfer K, Radke M (1990) Open-pore sintered glass as a high-efficiency support medium in bioreactors new results and longterm experiences achieved in high-rate anaerobic digestion. Water Sci Technol 22: $25-32$
12. Yee CJ, Hsu Y, Shieh WK (1992) Effects of micro carrier pore characteristics on methanogenic fluidized bed performance. Water Res 26: 1119-1125.

13. Sowmeyan R, Swaminathan G (2008) Evaluation of inverse anaerobic fluidized bed reactor for treating high strength organic wastewater. Bioresour Techno 99: 3877-3880.

14. Sowmeyan R, Swaminathan G (2008) Performance of inverse anaerobic fluidized bed reactor for treating high strength organic wastewater during startup phase, Bioresour Technol 99: 6280-6284.

15. Buffiere P, Bergeon J, Moletta R (2000) The Inverse Turbulent bed: A Nove Bioreactor for anaerobic Treatment. Water Research 34: 673-677. 